\title{
Detecting Supply Chain Innovation Potential for Sustainable Development
}

Raine Isaksson
Peter Johansson
Klaus Fischer
ABSTRACT. In a world of limited resources, it could be argued that companies that aspire to be good corporate citizens need to focus on making best use of resources. User value and environmental harm are created in supply chains and it could therefore be argued that company business ethics should be extended from the company to the entire value chain from the first supplier to the last customer. Starting with a delineation of the linkages between business ethics, corporate sustainability, and the stakeholder concept, this article argues that supply chains generally have a great innovation potential for sustainable development. This potential could be highlighted with system thinking and the use of change management knowledge, promoting not only innovations within technology but also within organizational improvement. We propose process models and performance indicators as means of highlighting improvement potential and thus breaking down normative business ethics' requirements to an opertionalizable corporate level: Good business ethics should focus on maximizing stakeholder value in relation to harm done. Our results indicate that focusing on supply chains reveals previously unknown innovation potential that seems to be related to limited system understanding. The assumption is that increased visibility of opportunities will act as a driver for change. Results also highlight the importance of focusing on sustainability effects of the core business and clearly relating value created to harm done.

KEY WORDS: measurement system, supply chain, sustainability indicators

\section{Introduction}

This article deals with organizational innovation for improving the sustainability in supply chains. Innovation is dealt with broadly, as including product and process innovation. Focus in this paper is on process innovation. Effective change is more in demand than ever with the many pressing needs for increased sustainability. Global heating due to increasing carbon emissions is one of the great challenges of humanity. The problem and its causes are well understood. Still, reports on the level of emissions indicate that we are currently following the worst case scenario of the International Panel for Climate Change report from 2007, without any imminent progress in sight. One interpretation of the causes to change failures is that the scope of the change has not had enough width and breath (Hall et al., 1993). This could be interpreted as lack of system understanding. Imada (2008) unveils several barriers on the way to sustainable development (SD) which might possibly be tackled with the knowledge of change management. For example, change management allows overcoming barriers of behavior especially in situations when no direct needs for change are perceptible and everything seems to be "ok."

Adapting a process view in organizations is claimed to have greater benefits when the processes cross several functions (Rentzhog, 1996). Functional focus tends to lead to sub-optimization and thus it could be argued that the larger the scope of the processes that are covered in a process management approach, the larger the potential should be. One example of this is Supply Chain Management where not only functional but also organizational boundaries are crossed (Skjott-Larsen et al., 2007).

It could be argued that a prerequisite for any improvement is that it can be visualized. It is hard to argue for improvements if we cannot see the problem or the opportunity. One way of describing organizations is to see them as process-based systems and to focus on the value per harm delivered (Isaksson and Hallencreutz, 2008; Isaksson et al., 2008). A question 
is whether we could improve the drivers of change toward sustainability by process-based system models that more clearly visualize and describe supply chains and supply chain innovation potential?

\section{Methodology}

We are basing this study on previous research within process management and system thinking for SD, where six important areas for further research have been identified (Isaksson et al., 2008):

- creating working definitions for sustainability and SD

- creating a generic system based model

- creating generic measurements

- managing corporate social responsibility (CSR) in the supply chain

- $\quad$ system-based knowledge management

- change management for SD.

In this article, we focus on how change management for SD could be improved by stronger drivers resulting from better models and better Key Performance Indicators. We have worked with theory development starting from some basic hypotheses, from business ethics, stakeholder, and systems theory as well as quality management. We use reasoning and theory input to choose generic indicators describing the "level of sustainability" of value creation in a supply chain. The generic indicators are translated for two supply chains. We have exemplified the following supply chains:

- building material supply chains based on cement and concrete (two examples)

- mobile communications supply chains.

The reason for choosing these supply chains is partly their importance and partly the possibility of the access of information. The building material supply chain is worldwide responsible for about $40 \%$ of the energy consumption and $40 \%$ of global carbon emissions (WBCSD, 2008). The level of change required is enormous. Mobile communications are important for the effectiveness and efficiency of all societies. The supply chain is global and criticized for its impact in the developing world. Detecting improvement potential in the mobile communica- tions supply chain could indicate future benefits for individuals, societies, and others. For both of these supply chains, we have discussed indicators to exemplify value/harm.

\section{Theory background}

\section{Business ethics and corporate social responsibility}

We interpret CSR as organizational promotion of global sustainability; see Garvare and Johansson (2009). For the contemporary organization, ethics is one of the interests adapted by stakeholders. The ethical organization could be described as treating stakeholders with honesty, fairness, and respect with a long-term focus aiming to satisfy the interests of all stakeholders [see Foley (2005) for a discussion concerning ethics as a stakeholder interest). For the organization to be sustainable, it needs to meet stakeholder requirements regarding ethical behavior. But beyond the question how to behave in an ethically sound way according to stakeholder requirements, business ethics also searches for answers how morality and self-interest can be balanced for attaining mutual benefit.

Suchanek (2008) emphasizes that ethics does not always pay off and that the alignment of corporate success and responsibility is one of the central challenges of a "good management." He further argues that self-interest is first of all a legitimate characteristic of all social beings, including corporations. This means that "profit" and "morality" per se are no antagonists as economic success lies in the legitimate self-interest of a company. But self-interest needs to be handled reasonably and not all kinds of self interest can be justified. Suchanek (2008) therefore proposes a certain ethical standard that is compatible with different global value systems (coming from various cultures and religions) and also with modern management concepts such as CSR or (corporate) sustainability. This "golden rule" calls to "Invest in the conditions which foster social cooperation and mutual benefit" (Suchanek, 2008, p. 4). Such a highly compatible ethical standard particularly fits with the question of sustainability in globally spread supply chains, where different cultures and social systems get linked through the principle of global labor division and where different management concepts/cultures 
clash. Thus, this universal ethical principle shall be taken as a basis for the following discussion. Thereby, we try to break down this rather abstract principle to a concrete management of sustainability innovation potential and thus to operationalize it by referring to well-known management concepts as well as by developing own concepts for the indication and measurement of sustainability.

\section{Identifying stakeholders for a discussion on CSR and $S D$}

In a world of limited resources, it is hardly possible to meet the interests of all potential stakeholder groups and compromises are needed. The above mentioned relationship between self-interest and morality of a company needs thus to be carefully balanced as an investment in the corporation's integrity. Realizing the principle of investing in conditions of mutual benefit first of all requires to further differentiate the term "stakeholders." Only when a company is aware of the different kinds of stakeholder groups it has or could have, it can reflect on the impacts of its behavior more thoroughly.

Quality requirements are normally defined by customers. Further requirements addressing the sustainability of value creation and an organization's outputs could be defined by other stakeholders and interested parties. Stakeholders are here defined as in Garvare and Johansson (2009) to be those actors that provide essential means of support required by an organization and who can withdraw their support if their wants or expectations are not met, thus causing the organization to fail or inflicting unacceptable levels of damage. Addressing stakeholders is thus a basic business consideration. Interested parties are all actors with any interest in the organizational activities, output, or outcome, but who do not possess the power or instruments to influence the state of the organization or its stakeholders. From business purposes, at least in the short run, interested parties could be ignored, but it would probably not qualify as good ethical behavior. The term "primary stakeholders," is used to describe actors that have direct control of essential means of support required by the organization. Depending on the context, examples of such primary stakeholders could include customers, management, co-workers, suppliers, share- holders, and government. "Secondary stakeholders" are individuals or organizations that, in one way or another, if their wants and expectations are too heavily violated, are able to influence primary stakeholders to withdraw essential support, thereby causing the organization to fail, or inflicting unacceptable levels of damage. This could include non-government organizations, academics, media, fair-trade bodies, environmental pressure groups, etc. (Garvare and Johansson, 2009).

Regarding SD, the interested parties of an organization as well as its natural environment share the common characteristic that both are affected by organizational activities (mostly in a not-sustainable manner) and do not have the possibility or power to react and sanction the organization. In contrast to human actors, nature is not an interested party as it cannot interact consciously with the organization and does not have interests as humans do. This view could be criticized of being very human centric with nature only having a role as supplier of services. It could be discussed if the interest to exist relies on the capability of expressing this desire. Also, nature when abused can retaliate by not performing customary eco-system services such as providing bees for pollination, providing rain, supplying fresh water, and maintaining a habitable climate. However, both interested parties and nature are linked to other groups which are able to act as stakeholders that can bring attention to their needs ${ }^{1}$ as well as to take action if those are not met. These groups can, e.g., be secondary stakeholders like NGOs who claim for human rights in global value creation (and thus the rights of interested parties) or environmental protection. These secondary stakeholders finally depend on coalitions with primary ones as the organization's customers or legislative bodies. Of course, the mentioned advocating groups can only represent an interested party's needs, respectively, the requirements of ecological sustainability in an indirect manner. The effectiveness of this representation depends - beside the willingness to act highly on the expertise of such an advocating group, meaning sufficient and valuable information about the necessary changes to SD.

Thus, stakeholders claiming for certain issues regarding social or ecological sustainability do not necessarily promote SD, even when their interests are met. This can be seen in the current debate on 
the increasing use of bio-fuels, fostered by the intended minimum shares of renewable energy through European legislation (acting as a primary stakeholder). The original objective to protect climate is actually challenged by the (possible) sideeffects of an increasing global cultivation of energy plants which may lead to severe social as well as environmental harm. Adequate information about value and harm of an increased global biomass production is necessary to enable politics as a primary stakeholder here. Another example is that of pressure groups, which throw light on social or environmental grievances. Besides the general problem that those pressure groups are normally not legitimated democratically, final customers responding their advices might not know if these are really effective regarding SD or not. Adequate indicators for SD might be able to improve the expertise of this stakeholder group.

The situation for the ethically inclined corporation is not simple when it tries to assess which demands from interested parties are legitimate in the context of SD. The best way forward could be to understand the system in which the company is working identifying value produced and harm done.

\section{Change management knowledge for $S D$}

Realizing more sustainable paths of economic and societal development requires changes of behavior and organizational as well as technological innovations (Zink et al., 2008). When "sustainable development" is understood as a politically enforced "top-down approach," this does not really allow long-term and far-reaching changes (Imada, 2008). This could be avoided by applying some fundamental principles of change management, supporting change toward sustainability. Change management hereby focuses on behavioral aspects and barriers, being it in the case to persuade people of "sufficiency strategies" or the adoption of technological innovations in social systems (as, e.g., the use of energy-saving electronics in households). Change management allows overcoming barriers of behavior especially in situations when no direct needs for change are perceptible. This is often the case with problem fields of SD such as climate change or other global problems that are emerging in the long run.
Generally, it can be said that things perceived as acute problems receive greater focus - "the squeaky wheel gets all the attention." Consequently, it could be assumed that there are many dormant opportunities for improvement waiting. Thus, it is important to clearly indicate the problem of the existing situation as well as the opportunities of improvement. This can only be done when sufficient information is available regarding the processes intended to be changed. There are three kinds of information being necessary in successful change processes (Böhnisch, 1975), see Table I. They allow reducing the uncertainty of change processes and thus promote the understanding and conviction regarding change.

Processes and supply chains exist as networks of activities where value is created, irrespectively of whether anybody has identified and documented these or not. Being able to visualize improvement potential could become a driver for change, especially if somebody is appointed as process owner and thereby as owner of the supply chain improvement. System models including relevant indicators could help in visualizing the why and what of change as well as the effects of change.

A systems perspective on process ownership for sustainability

In a systemic/cybernetic understanding, sustainability can be seen as a system configuration called viable. Viability here first of all means that the system can steadily sustain a certain intended configuration (thus viable does not mean that the system is only survivable; Malik, 2008). For the human population, this configuration can be called "sustainable development" as this concept claims for the satisfaction of the needs of all humans, living now and in future generations (WCED, 1987). In the corresponding viable systems model (VSM) of Beer (1985, 1995), all viable systems are isomorphic by following the same general structural principles. Beer modeled the structure of various viable systems and searched for their similarities. The basic assumption for the modeling thereby was the concept of invariance, meaning that the structural principles of natural systems can be transferred to social systems. In the original context of the model, these are organizations, but as the 


\section{TABLE I}

Categorization and objectives of information required for successful change, adapted from Böhnisch (1975)

Type of information Objective of the information

Information about the reason for change:

Why shall we change?

Information about the subject of change:

What will be changed?

Information about the consequences of change:

Which are the effects of the change?
Better understanding of the problem, recognition of the necessity and the sense of the change

Clarification and knowledge about the (chosen) alternatives

Objectifying the (personal) assessment of the change,

clarification of the (personal) consequences recursion level of the model can be changed (Beer, 1995), these systems can also be supply chains or supply networks as focused on here. Following Beer's theory, all viable systems include five different functional "parts," called system 1-5 (see Figure 1).

When we argue that supply chains do often not have a clear "process owner" who is taking care of the overall systems prosperity (could be at the supply chain level but also at the global level), we address, in the terms of the VSM, the missing or not adequately performing system 5 . System 5 has a moderating function and formulates the policy of the overall system, thus it takes care of that inner and external orientation is balanced and that the overall system is sustained (Beer, 1995; Probst, 1981). The normative and balancing functions of system 5 are indispensable, as the other subsystems cannot estimate to what extent they have to contribute to the overall system's viability. Transferred to the context of supply chain innovations for SD, system 5 would take care that not only local but also global optima regarding sustainability can be realized. As the "thinking chamber" (Beer, 1995) of the overall system, it would act as a driver for the mentioned necessary change and innovation processes toward SD. Thus, it could be argued that a company aspiring for being a good corporate citizen should take active part in the "thinking chamber" work.

Isaksson and Steimle (2009) propose working definitions for SD and Sustainability. The term True Sustainability is used for a situation corresponding to the viability according to VSM. The rate of improvement to reach viability in time before irreversible damage has been done is defined as True $\mathrm{SD}$, see Figure 2.
The value per harm concept for sustainability measurement

One possible way of generalizing indicators is to use the Eco Efficiency concept as a base - producing more value per harm (WBCSD, 2000). The value can be extended from the original sales value to include all stakeholder value (Isaksson and Hallencreutz, 2008; Isaksson and Steimle, 2009). For each system, a possible simplification is to focus on the main stakeholders and their values and the main harm. In a world with shrinking resources, it could be argued that the customer is often the most important stakeholder. A comparison could be made to war times where authorities intervene and organize rationing of what are basic needs for survival of the population and where corporate needs are put on hold.

An organization could be described as a processbased system (Isaksson et al., 2008). Outcome in Figure 3 is the level of stakeholder satisfaction. The signal from stakeholders and interested parties becomes a feedback to the organization. On its way, it passes a filter consisting of the external resources that describe the external organizational environment. Here, things like country and branch factors are indicative. Customers might be complaining and the environmental effects could be bad, but this might not translate into drivers for change if, for example, the organization is a monopoly working in a corrupt country.

The definition of sustainability proposed by Juan R. Pujol is "creating value without destroying value" which we have interpreted as value per harm where the harm component is zero. This is practically impossible and in the real world we would always have some harm component. The two 


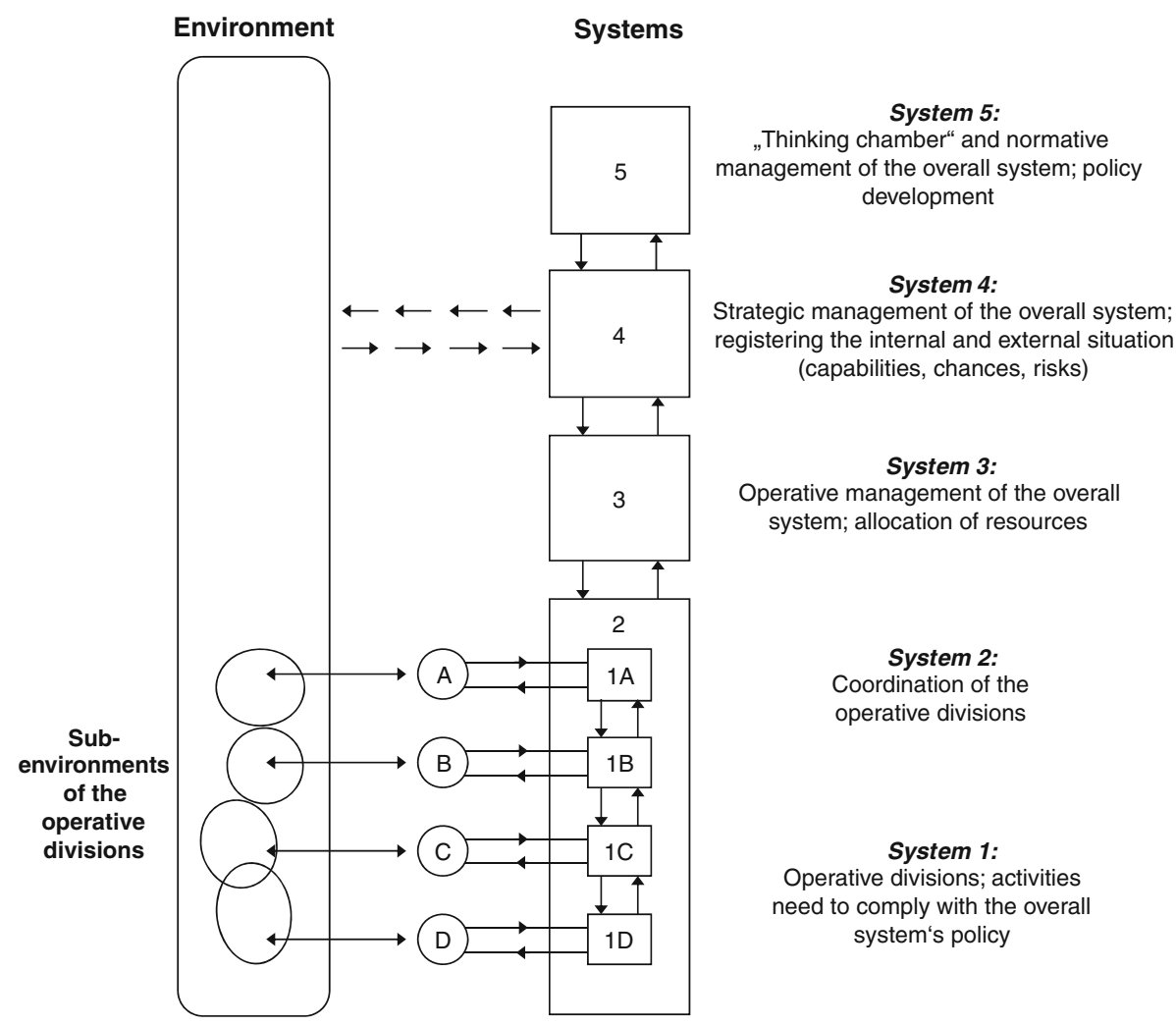

Figure 1. General structure of the Viable System Model (according to Beer, 1995; simplified structure) and systems' functions (according to Malik, 2008; Probst, 1981; Wilms, 2003).

\section{Performance}

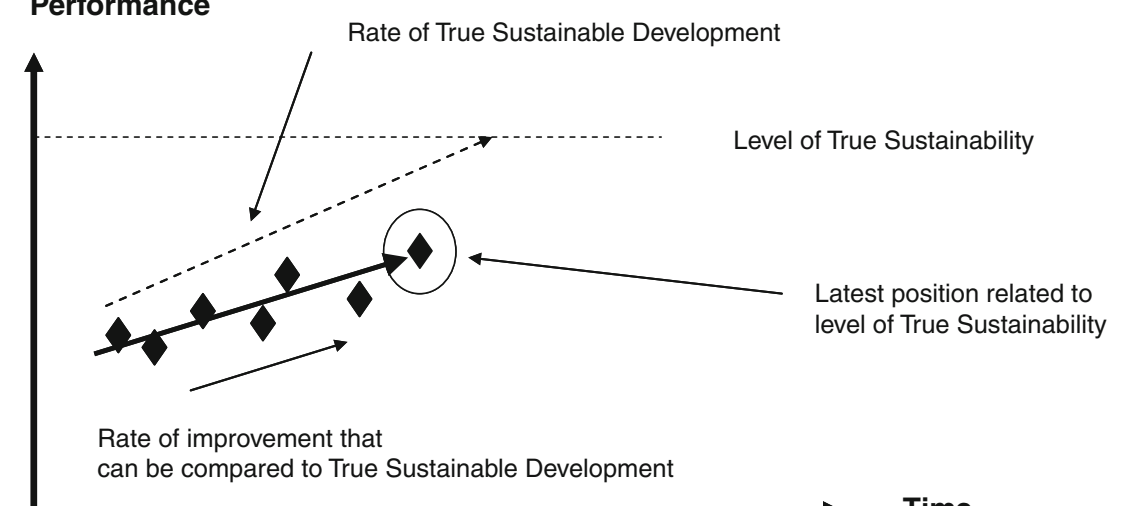

Time

Figure 2. Working definitions for True Sustainable Development and True Sustainability (Isaksson and Steimle, 2009).

indicators of interest would be total harm done and the value created per total harm. This has then been further developed into a structure of a simplified Triple Bottom Line (TBL) consisting of value produced, value per environmental harm, and value per social harm (Isaksson, 2007; Isaksson and Hallencreutz, 2008; Isaksson and Steimle, 2009).

The slightly controversial argument is seeing part of the social harm as the price paid for a product. For the majority of the world, which is poor, the price of 


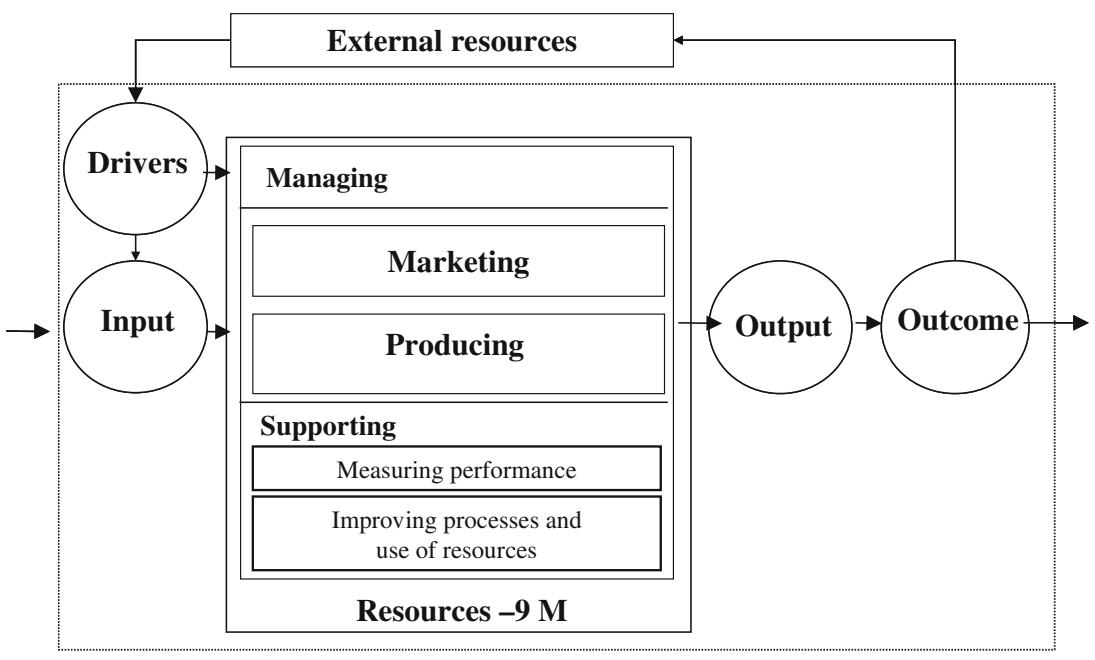

Figure 3. Process-based generic system model for organizations, adapted from Isaksson et al. (2008).

basic goods such as food, building materials, and clothes is crucial. With small margins, higher prices will directly reduce the purchase of basic goods and will lead to increased social harm. It could therefore be argued that a socially responsible company works to maximize user value in relation to price. This is what is implied in the thinking called the "Base" or the "Bottom of the Pyramid," which advocates focus on the very poor because they are both an untapped marked and socially disfavored by high prices (Prahalad, 2006). This can only be done when the company has the right products and produces them in the right way, which means having low costs of poor quality (Isaksson, 2005). It can be argued that focus on quality, in the form of minimizing the cost of poor quality, also is working for increased sustainability. We see CSR a something that covers the entire supply chain. This is an extension from the concept of Fair Trade that focuses on monitoring suppliers. It could be seen as good business ethics to monitor value and harm over the entire supply chain from the first supplier to the end consumer, especially the one at the Base of the Pyramid.

\section{Performance indicators for $S D$}

It has been said that in order to manage change you need to be able to communicate and in order to communicate you must be able to measure. To be able to measure you must be able to define and in order to define you must understand. We believe that this is correct and that without agreed definitions of SD and sustainability that are converted into some type of indicators it will be hard to improve. Isaksson and Hallencreutz (2008) argue that the maturity of the measurement system is an indicator of existing improvement potential - the lower the maturity the higher the unrealized potential for improvement.

Performance indicators based on the value/harm logic could to start with be mainly related to output and outcome measurements, see Table II for a proposed measurement matrix. Resources in Table II have been described based on a 9M-checklist (Isaksson et al., 2008). Resources are both concrete and abstract. They are the necessary requirements for the process to work but are not inputs as such. They change little in the short time span but need to be managed in the longer time perspective. As an example, the management resource stands for the culture as a resource. This normally is constant or practically constant over a number of process cycles. One way of assessing this is to look at policies both written and enacted. Methods in Table II describe the ways of working. A Method resource for environment is, for example, an environmental management system based on ISO 14001. 
Raine Isaksson et al.

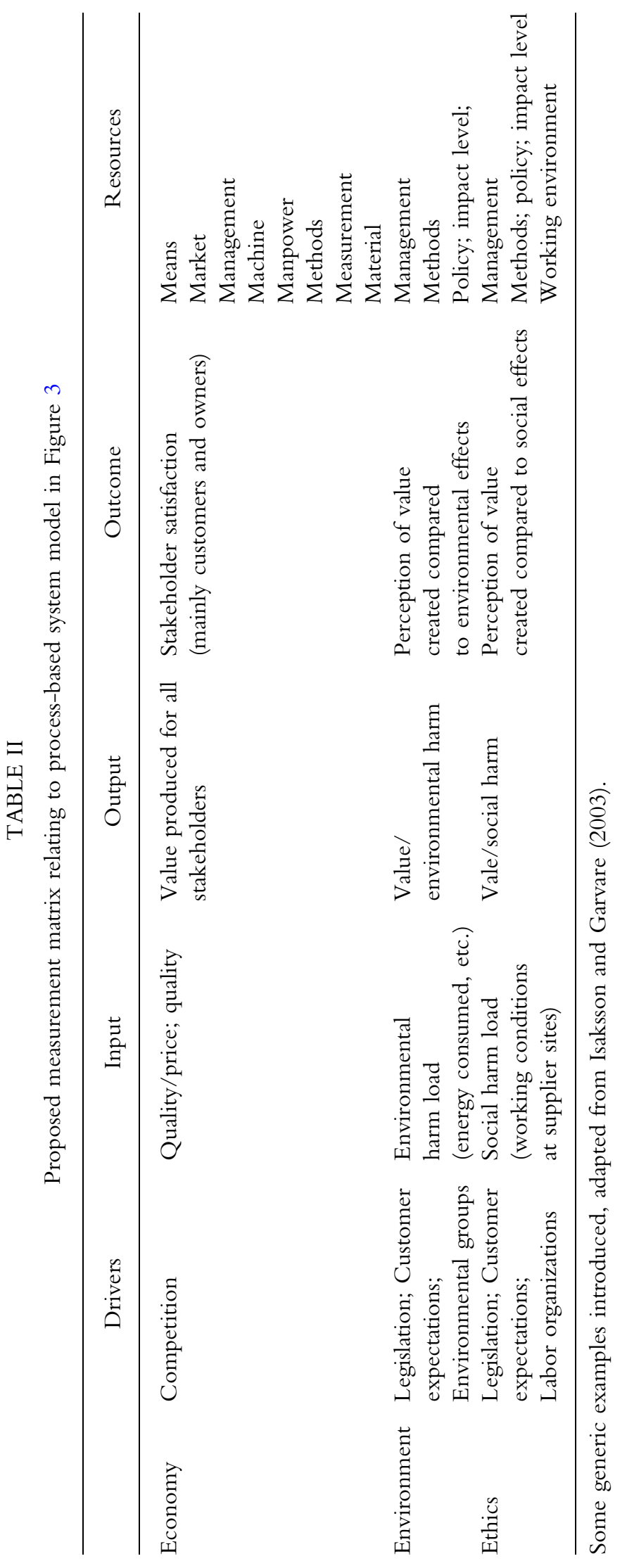


Producing in Figure 3 should be seen as adding value in the form of goods and services. The outcome is equal to the stakeholder or interested party perception of the output. With customers in focus, it would be the user of the product that assigns the value for the output. This could be put into question when the customer preference is in conflict with the common good. However, this discussion is not part of this article.

An indicator system which is based on the "value per harm" concept would thus provide for an important precondition for the establishment of a system 5 (see Figure 1) in global value creation networks. It allows recognizing and visualizing a "sustainability quotient" which evaluates the respective economic processes.

In the further study, we concentrate on Output and the value per harm discussion.

\section{Synopsis: defining supply chain innovation potential} for $S D$

Most processes have a hidden potential in the form of unidentified opportunities. This can theoretically be defined for any process by comparing the actual level with a best possible performance - Opportunity Based Improvement (Isaksson and Taylor, 2006). According to Joseph Juran, the cost of poor quality is zero when processes and products are perfect. This results in a first indication of the magnitude of improvement potential - difference between actual and zero cost of poor quality. The focus on SD affects all organizations and it also affects innovation by extending the purpose from focus on economic gains to the broader view of the TBL. The three TBL dimensions of economic prosperity, environmental protection, and social responsibility are commonly used to describe work with SD in organizations. We propose to focus on the relation value produced per environmental and social harm done for the customer. Our interpretation, based on previous reasoning, is that SD takes us to a state of sustainability or viability. The current situation is not viable and we need to improve the lot of a great part of the population in the world without destroying the conditions for future viability. In other words, we need to maximize value in supply chains and minimize harm in them with the condition that there is a maximum limit for the total harm and a maximum limit for the harm done to every interested party. Value in this context should be seen broadly as the total value created for all stakeholders and interested parties with the organizational priorities being focused on stakeholders. Harm is divided in environmental harm and social harm. From a business ethics point of view, minimum levels for all interested parties should be defined. Innovation potential is here described as possibilities to increase the ratio of value produced to harm done.

\section{Application to supply chains}

\section{The housing supply network}

The building supply chain is included in the supply network for providing housing, see Figure 4. With a supply network we want to indicate that when it comes to service processes, they are better described as networks than chains. The main effects from this supply network are designed in during the building process. The building materials themselves account for only some $10-15 \%$ of the total energy consumption and carbon emissions (WBCSD, 2008). The main effects result from the use of buildings, mainly in the form of heating and cooling. However, the design of the building sets the prerequisites for later energy use.

Isaksson et al. (2008) use a case study from Iran to illustrate the importance of considering the whole supply chain. The technical improvements targeted for the cement industry in the form of lower energy use in cement manufacturing were expected to result in improvements in the range of $5-10 \%$, with the challenge being much greater. Focus on the entire supply chain, including city planning, with focus on improving the quality of cement, concrete, building design and focus on extending the life span of buildings could reduce the effect from building materials with some $50-90 \%$. This is using $\mathrm{m}^{2}$ living space as value and $\mathrm{CO}_{2}$-emissions from the supply chain as harm. Lack of supply chain focus for the building supply chain in Iran could in the worst case mean that less than half of the building potential of cement is used, while simultaneously generating the same amount of $\mathrm{CO}_{2}$ at production. The causes for this can be qualitatively assessed using the $9 \mathrm{M}$ checklist. The main cause would be the Management 


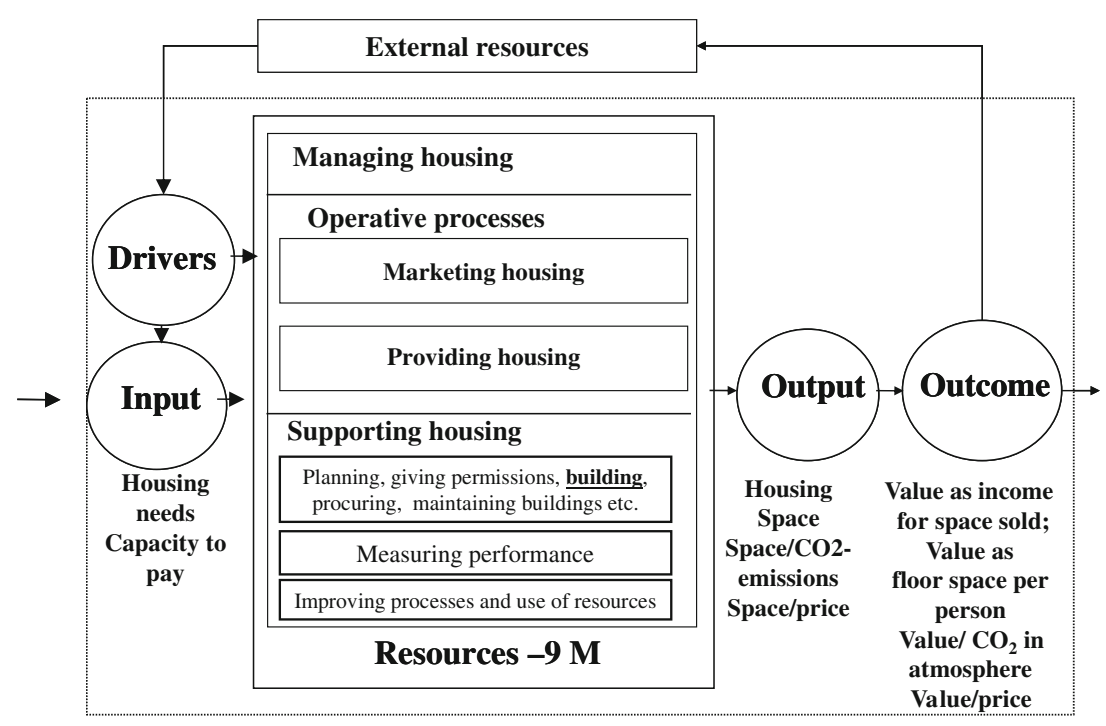

Figure 4. Application of the system model in Figure 3 on the housing supply chain.

where the functional control by different ministries makes it very difficult for introducing systemic thinking. Also, the use of supply chain management as part of Method is not developed and furthermore the Measurement system is not encouraging systemic thinking. One example of this from the work in Iran was the goal setting by the state on manufacturing sub-processes. There was a requirement that the energy consumption of a cement plant clinker kiln should be as low as possible, but at least $<800 \mathrm{kcal} /$ $\mathrm{kg}$. This was in the studied plant achieved by producing clinker with inferior strength potential. The value of the clinker produced was reduced to save energy which affected the next process of cement milling where a higher clinker percentage was needed to give the required cement strength. Measured as building value produced by energy used the practice was a failure, but measured as tons of clinker produced per energy used, the result was good. Would the measurement have been on strength tons compared to energy consumption the sub-optimization would have been obvious.

\section{Block making in Dar es Salaam}

In many developing countries, especially in urban areas, concrete blocks are the most commonly used building material. Existing housing standards are often inadequate, and with increased urbanization the needs for concrete will increase. Especially in third world countries, the per capita consumption of cement increases with the GNP/capita. Major cement manufacturers estimated that $80-90 \%$ of the increase of cement use will be in Third World markets. This means that when general development activities are successful it drives building activity, and with it, the use of cement. One way of measuring the value is to look at available $\mathrm{m}^{2}$ per person and year. This is the customer or user value. The main harm could be linked to energy used or the carbon emissions. With growing economies, building activities in the urban centers of Africa will also increase considerably. Concrete is the most commonly used material after water with a worldwide per capita consumption of some 3 tons per person and year (WBCSD, 2004). In African cities, concrete and concrete blocks are a dominating building material. About $5-20 \%$ of the concrete weight is cement, which has a considerable carbon dioxide $\left(\mathrm{CO}_{2}\right)$ footprint. The world cement industry is responsible for $5 \%$ of the total worldwide man-made carbon dioxide emissions. The most expensive component, cement, also has the largest carbon footprint. One ton of cement causes close to 1 ton of $\mathrm{CO}_{2}$ emissions, which makes right use of cement in concrete crucial. This puts focus on good use of cement, with focus on getting maximum value out of it to 


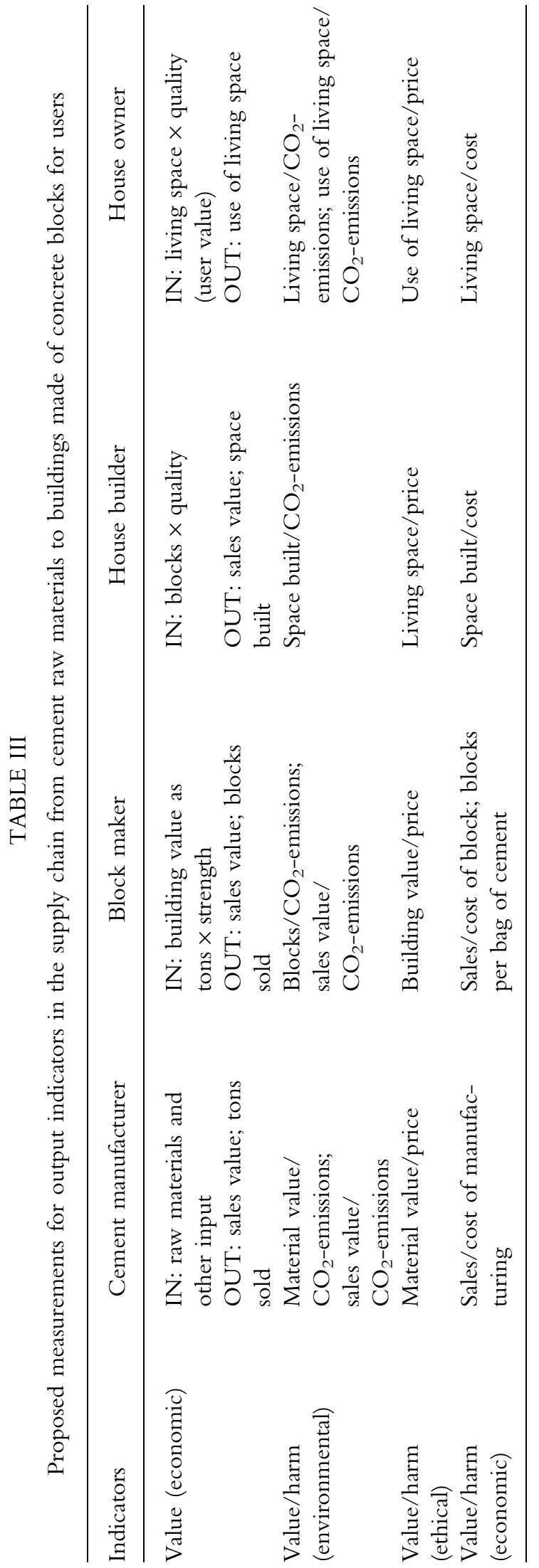

justify the emissions. Making best use of cement in concrete has effects both on environmental and social indicators. Non-optimal use of cement in concrete results in less building value per environmental harm and lower performance per price paid.

Third world supply chains are still in many cases undeveloped due to different reasons. The supply chain from cement-based raw materials to blocks ready at site to be used in buildings includes many steps with risks of losses. Isaksson (2005, 2007) indicates that on the level of cement manufacturing there seems to be a considerable improvement potential in producing more user value with the same resources. In Table III, some indicators are proposed based on the ideas of a simplified TBL of value, value per environmental harm, and value per ethical harm (Isaksson and Hallencreutz 2008). Additionally, a third harm has been added - the economic harm representing costs. This was done in the progress of work as a logical addition.

The supply chain described in Table III starts with cement raw materials and ends with a ready building that is in use. For private houses making up a large part of the customer base, the costs for cement and blocks are very important, which justifies the focus on these. The stakeholders focused on are suppliers, producers, and customers with many having multiple roles. For the economic value, INPUT and OUTPUT in the process have been defined. What is sales value for the supplier is product cost for the customer, which is converted to user value per cost as an indicator. Logically, a customer focused company would keep track of the user value provided. With focus on CSR, main environmental and social harm should be tracked. Value and harm can then be compared as, for example, building value per carbon emissions.

The building value for cement can be assessed relatively easily as the strength potential of the cement. A benchmark for this can be calculated as an interpretation of the virtual state of zero quality costs with perfect products and perfect processes (Isaksson, 2007). Using a similar logic, Isaksson (2005) shows that cement performance in many cases is only about $70 \%$ of a benchmark and that average price in three studied African countries is the double per ton sold compared to a benchmark. For Tanzania, the Q-performance of cement is assessed to be $75 \%$ and the price is about $220 \%$ compared to a world 
benchmark. This means that the building value/ price is about $35 \%$ of best performance for the block maker. Studies of block making in Dar es Salaam show that the quality performance is about $75 \%$ compared to a benchmark (Isaksson and Taylor, 2009). With cement and blocks performing each to $75 \%$ this means that only about $50 \%$ of a benchmark cement building value is transformed into blocks. This is not counting with losses in transport and building. The costs of block making have only been studied superficially so far in an ongoing research project.

The city of Dar es Salaam uses some 600,000 tons of cement for block making per year. This corresponds roughly to some 300 million solid blocks of about $30-35 \mathrm{~kg}$ to a sales value of about 240 million US $\$$. Based on the assessment above, about $50 \%$ or about 120 million US\$ in building value are lost as costs of poor quality. Additionally, the price for the end customer is at least doubled due to process inefficiencies that increase costs and result in higher prices. For the product performance, making a benchmark cement and benchmark block would most likely not increase the carbon emissions, but might even lower them. This means that the number of blocks per ton of carbon emissions could be doubled or that twice as many blocks could be produced with the same carbon footprint. Results for the quality performance potential in block making are summarized in Table IV, for cement making in Table V, and a summary is presented in Table VI.

Table IV indicates that 26 million US\$ of more value could be produced and 120,000 tons of $\mathrm{CO}_{2}-$ emissions reduced by focusing on good block manufacturing practices in Dar es Salaam.

Less cement of a higher performance could be used to make the same amount of blocks. Potential is negative for the cement producer at a stable market. However, with high building needs more material will be sold provided cement and blocks become cheaper. Until 2009, cement production capacity has been a limiting factor, which partly explains the high price.

In Table VI, the quality-related improvement potential is summarized indicating costs of poor quality in the range of $40 \%$. The potential for the stakeholder block customer is even higher. Block customers currently pay 240 million US $\$$ per year. Would this be a product competing in a market with best performance the price should only be 60 million US $\$$, or a user value per price of only $25 \%$ of best performance. Consequently, the relatively poor inhabitants of Dar es Salaam pay about four times as much for their block products as the mostly richer customers do in a developed market. The reason for this could be seen mainly as underdevelopment of the supply chain with the lack of a good overview and lack of clear responsibility for improvement. Looking at the causes for the existing potential, it could be said that African markets for building materials are far from ideal markets, which results in high prices both in absolute terms and in terms of performance to price. There should be an incentive for the key stakeholders that are the cement manufacturer and the block makers to improve performance in the supply chain. Ideally cost gains could be split between producer and customer. Lower

TABLE IV

Comparing cement costs and $\mathrm{CO}_{2}$-emissions at the same level of production and same quality for blocks

\begin{tabular}{|c|c|c|c|c|}
\hline & $\begin{array}{l}\text { Building value } \\
\text { (million blocks) }\end{array}$ & $\begin{array}{l}\text { Cement cost } \\
\text { (million US\$) }\end{array}$ & $\mathrm{CO}_{2}$-emissions (tons/year) & Comments \\
\hline Actual & 300 & 120 & 540,000 & $\begin{array}{l}\text { Assuming current quality } \\
\text { and price of cement }\end{array}$ \\
\hline Benchmark & 300 & 94 & 420,000 & $\begin{array}{l}\text { Block production would probably } \\
\text { increase if prices were reduced }\end{array}$ \\
\hline Potential & 0 & 26 & 120,000 & $\begin{array}{l}\text { The cost potential would ideally } \\
\text { be shared between manufacturer and customer }\end{array}$ \\
\hline
\end{tabular}

The benchmark is at best quality for blocks. 


\section{TABLE V}

Comparing cement building performance and $\mathrm{CO}_{2}$-emissions at the same level of cement building value production with improved cement quality

\begin{tabular}{lrrrl}
\hline & $\begin{array}{c}\text { Cement production } \\
\text { for blocks }\end{array}$ & $\begin{array}{c}\text { Cement cost } \\
\text { (million US\$) }\end{array}$ & $\begin{array}{c}\mathrm{CO}_{2} \text {-emissions } \\
\text { (tons/year) }\end{array}$ & \multicolumn{1}{c}{ Comments } \\
\hline Actual & 600,000 & 120 & 540,000 & Assuming current quality and price of cement \\
Benchmark & 450,000 & 90 & 405,000 & $\begin{array}{l}\text { Improved cement quality with current price } \\
\text { Cement production would not be reduced } \\
\text { Potential }\end{array}$ \\
& $-150,000$ & 30 & 135,000 & if prices were lowered \\
\hline
\end{tabular}

TABLE VI

Quality and environmental potential in the supply chain from cement raw materials to concrete blocks for producing the current 300 million blocks per year

\begin{tabular}{|c|c|c|c|c|}
\hline & Cement use & $\begin{array}{c}\text { Cement } \\
\text { cost (million US\$) }\end{array}$ & $\begin{array}{l}\mathrm{CO}_{2} \text {-emissions } \\
\text { (tons/year) }\end{array}$ & Comments \\
\hline Actual & 600,000 & 120 & 540,000 & Assuming current quality and price of cement \\
\hline Benchmark & 340,000 & 68 & 300,000 & Improved quality of cement and blocks with current price \\
\hline Potential & $-240,000$ & 52 & 200,000 & $\begin{array}{l}\text { Cement production would probably not be } \\
\text { reduced if prices were lowered }\end{array}$ \\
\hline
\end{tabular}

prices would in this type of market with important building needs, lead to increased sales. One of the reasons for the existing potential could be that it is not visualized - the Measurement resource is not developed. The strongest and most influential participant is the cement producer. In the ideal situation, the cement industry, often a subsidiary of a multinational corporation, should take responsibility for seeing that building materials reach all customers and especially the poor in good and affordable condition. For a company aspiring to have good business ethics working with making best use of resources in the supply chain could be seen as a necessity.

Following only the logic of focus on stakeholders, there is no apparent need of doing this. The higher prices for a lower performance are paid by the end customer who is a marginalized interested party. The environment in the form of an increasing carbon level in the atmosphere only becomes an interested party if advocated by some groups. Third World industries are to quite some extent free from this type of scrutiny. The previously reviewed theory for stakeholders and interested parties could therefore be said to describe the actual situation. However, it could be argued that it is part of a company's CSR to manage the entire supply chain. With scarce resources, it is likely that companies who are not managing the use of resources well will lose their "license to operate." Primarily, this would mean public disrespect resulting in loss of brand value, but it could also lead to more serious problems like loss of permits to operate. It could therefore be argued that good business, in the long run, is the ethical one.

\section{Mobile communications supply chain}

The mobile handset industry has gone through significant change and growth during the last decade, from being a heavy and expensive device for making a random call to a multimedia device in the hands of everyone in the western world. The usages of mobile handsets are also increasing in the developing world, where it is currently used more as enabler for 
communication than multimedia. During 2007, 36 mobile phones were produced each second and in total over 1 billion mobile phones were produced (SOMO and Swedwatch, 2008). Being able to use mobile communication could be considered as value for the user, it is also an enabler for an effective society. Nokia, the world's largest mobile phone manufacturer, describes their view of possible benefits of mobile communication in their annual report

\begin{abstract}
Mobile communications have the potential to bring both social and economic benefits at the same time enhancing economic development and improving quality of life. Mobile phones offer far more than the ability to make calls. Billions of people in the developing world live in remote and rural communities without access to healthcare or education, transport and up to date news - let alone banking or financial services. Mobile phone networks have the potential to transform the delivery of these services and make them available to many more people. (Nokia, 2007)
\end{abstract}

There are examples in emerging markets where the usage of mobile phones have enhanced the economic situation, for example, by being able to sell food and merchandise at the right place and time. The number of sold units in the developing countries is expected to increase significantly in the future. The potential is large as around $80 \%$ of the population is calculated to live in areas covered by GSM networks (Nokia, 2007). Affordability is one of the most important factors to enable mobile communication to people living on low incomes.

The biggest mobile phone producers; Nokia, Motorola, Samsung, Sony Ericsson, and LG do the final assembly of most mobile phones in house. However, most of the component production is outsourced to suppliers. This means that many of the value adding activities take place outside the direct control of the mobile phone companies, both at suppliers' and sub suppliers' production sites. The supply chain in the mobile handset industry is complex, from small electronic components like resistors and capacitors to LCDs and cameras and mechanical parts like keypads and plastic covers. The number of first tier suppliers in a mobile phone could range up to 200-300. The number of 2 nd and 3rd tier suppliers then grow exponentially for everything supplied to the 1st tier suppliers.
Most mobile phones are after being produced sold to retailers and mobile network operators that sell them to the consumers. This makes the ownership of recycling more unclear. Today most recycling initiatives are driven combined by network operators and mobile phone producers.

SOMO (2006) describes the main environmental aspects for producing the mobile phones as: toxic substances in components, the environmental footprint of mobile phone manufacturing, and electronic waste. The environmental footprint consists of usage of water, electricity, chemicals, and fossil fuels. One of the significant environmental aspects is the electronic waste, which has become the largest growing component of municipal solid waste (SOMO, 2006). The high rate of product development in the products and the short life length of mobile phones are contributing to the increasing amount of waste. According to SOMO (2006), most of the waste that is collected for recycling in the developed world is sent to China and India, there creating environmental problems in the recycling process. During the production of a mobile phone, $\mathrm{CO}_{2}$ emissions are low compared to the cement industry, but there are improvement opportunities.

Environmental and social issues brought up in media often concern working conditions at the manufacturing sites of suppliers further down in the supply chain. The working conditions have been criticized, for example, regarding compulsory overtime, poor usage of protection equipment, and financial punishments; see, for example, SOMO (2006), DanWatch (2008), and SOMO and Swedwatch (2008). It is hard for the mobile phone producers to control the CSR performance of the whole supply chain, efforts for increasing awareness and competence in CSR is necessary for the suppliers to be able to put CSR demands on their suppliers to achieve a sustainable supply chain. It would not be reasonable to demand that the operators or the mobile handset companies should control the CSR performance of all the suppliers in all tiers. Instead the requirements and knowledge must be managed throughout the whole supply chain. Less seems to be written on the responsibility of the mobile phone producer to assure that telephone usage can be done at an affordable cost.

From lifecycle assessment studies made by the mobile network company Ericsson (2007), the 


\section{TABLE VII}

Proposed measurements for output indicators in the communication supply network

\begin{tabular}{|c|c|c|c|}
\hline Indicators & $\begin{array}{l}\text { Telephone manufacturer } \\
\text { together with network } \\
\text { service provider }\end{array}$ & Manufacturing employees & User \\
\hline Value (economic) & $\begin{array}{l}\text { Sales value } \\
\text { Phones sold } \\
\text { User value }\end{array}$ & Salary & $\begin{array}{l}\text { Communication value (time, } \\
\text { content, availability) }\end{array}$ \\
\hline Value/harm (environmental) & Sales value/waste produced & Salary/waste produced & $\begin{array}{l}\text { Communication value/ } \\
\text { waste produced }\end{array}$ \\
\hline Value/harm (social) & $\begin{array}{l}\text { Sales value/worker harm } \\
\text { User value/price }\end{array}$ & $\begin{array}{l}\text { Salary/harming } \\
\text { working conditions }\end{array}$ & Communication value/price \\
\hline Value/harm (economy) & Sales value/cost of inputs & Salary/working time used & Communication value/cost \\
\hline
\end{tabular}

estimation is that approximately $0.14 \%$ of global $\mathrm{CO}_{2}$ emissions and approximately $0.12 \%$ of primary energy use are attributable to mobile communications. This compares with $20 \%$ of $\mathrm{CO}_{2}$ emissions and approximately $23 \%$ of primary energy use for travel and transport. Ericsson (2007) state that the annual $\mathrm{CO}_{2}$ footprint of the average mobile subscriber is around $25 \mathrm{~kg}$ - which is comparable to driving an average car on the motorway for one hour, or running a 5-W lamp for a year (Ericsson, 2007). This means that the positive effects from enabling communication could overcome the negative impact, for example, by preventing one journey with a car per year. From a system perspective of the whole supply chain, it is therefore considered more important to look at the cost of communication, which is a limitation for enabling communication in large parts of the world. The value for customers could therefore be described in terms of communication availability. This availability produced by a communication supply network comes at a price. It could be argued that the price of services has the largest social impact for poor customers. Comparing the number of potential poor telephone users with the numbers of employees working in the production chain indicates that an overwhelming majority of the stakeholders are poor users. With $80 \%$ of the population being within the reach of GSM and estimating World's poor population to about 5 billion this means about 4 billion potential poor customers. The number of people involved in mobile phone manufacturing is difficult to assess but is considerably smaller. The conclusion would then be that for the communication supply chain the main value is availability and the main harm is price of communication. This does not mean that other environmental or social issues should be overlooked, but that there should be more focus on the large players in the communication supply chain to assure that services are available for poor people at affordable prices as described with an example in the Bottom of the Pyramid (Prahalad, 2006). In Table VII, a measurement framework with the main identified stakeholders.

The environmental sustainability indicators labeled as waste could include number of discarded phones that are not recycled, the usage of hazardous chemicals and production waste. The social indicators would focus on employees in the supply chain but mainly on the large group of customers and the communication value they receive. Greenpeace presents a ranking of electronic supplier for the usage of hazardous materials in the mobile phones, see Greenpeace (2008). It could be indicator for environmental performance.

If looking at a mobile communication as a support process in the global system process the environmental impacts and social impacts are limited, and the benefits can compensate the negative impacts. This means that the prioritization of the sustainability indicators should be on creating maximum customer value for an affordable price.

One of the most recent environmental initiatives is the marketing of new "green" mobile phones; 
this sometimes refers to that the plastic parts are produced from recycled plastic resin or bio-resin. This is an initiative that would probably not be highly prioritized if system focus and not market opportunities were driving the sustainability improvement initiatives since the overall environmental impact of the plastic resin is rather limited compared to the environmental impact during the whole lifecycle. Finding and using appropriate value per harm indicators could here increase public awareness and help to focus sustainability improvement activities into areas with higher improvement potential.

\section{Conclusions}

The examination of two supply chains indicates that there could be a significant improvement potential which has not been clearly presented due to lack of system understanding. The level 5 management of the Viable Systems Model has not been achieved, see Figure 1. Creating sustainability indicators based on the idea of value per harm could be a feasible way of highlighting sustainability potential. Even with the results from the superficial review of two supply chains the indication is that lack of system ownership and lack of system measurements could mask an important sustainability potential. In other words, we think that there is an important innovation potential in improved visualization and measurement of value per harm in supply chains. In both supply chains studied, the results indicate that it is important to primarily focus on the core business and user value produced even more than on activities like recycling of mobile phones.

It seems that the sustainability indicators we are proposing could help in highlighting the existing potential as a prerequisite for innovation in supply chains for SD. Many supply chains have a complex structure and do thus rather act as networks of value creation activities. It is argued that a clear process ownership is often missing within these networks, leading to suboptimal processes. This is in particular the case regarding sustainability innovations in supply chains: As there is no "thinking chamber" of the overall supply chain system allowing reflexivity and to set-up common policy principles, the viability of the whole system is not guaranteed. A look on the Viable System Model shows that this can be seen as a certain lack of general systems functions (system 5). The proposed sustainability indicators could help to provide the necessary information to better establish this systems function within supply chains, either institutionalized through internal management systems or external actors as politicians or stakeholders and NGOs. It could also be argued that the strongest actor in the supply chain, often a multinational corporation should take lead as an example of genuine business ethics.

\section{Discussion}

We have presented ideas for future research where we think that there is a good potential for improving sustainability. Further iterations with fact finding are needed to confirm the initial indications. With focus on stakeholders only, the main harm of $\mathrm{CO}_{2}$ emissions would not be included since nature would only be present provided there are interest groups that are active, which they were not in the studied example of Block Making in Dar es Salaam. Carbon emissions are generally identified within the cement business as the main environmental problem. This means that governments and NGOs bring the issue into cement organizations. However, focus on carbon emissions is much less prominent in Third World plants. This could indicate a problem when improvement is based on needs of stakeholders and interested parties. Since cement customers are relatively small and with limited technical competence there is little focus on the cement building value. Customer pressure is mostly focused on quantity, which limits the cement manufacturer focus on quality. The indicator of building value is not used and not asked for. The same would probably apply for the large group potential but poor users of mobile phone communications. They might not even be interested parties. In order to make potential value to surface some external drivers in the form of NGOs or critical research could be needed. Most companies still would have focus on profit maximization, albeit coupled with compliance to rules and regulation on environmental and social performance. The question is how to gain acceptance for a strategy where companies focus on maximizing user value per harm 
done as the core of their sustainability work. From a business ethics perspective, such a strategy would be legitimated by the presented "golden rule" that calls for investments in the conditions that foster social cooperation and mutual benefit.

\section{Note}

11 The "needs" of the natural environment are here understood as those requirements leading to ecological sustainability.

\section{References}

Beer, S.: 1985, Diagnosing the System for Organizations (John Wiley \& Sons, Chichester).

Beer, S.: 1995, Brain of the Firm, 2nd Edition (John Wiley \& Sons, Chichester).

Böhnisch, W.: 1975, 'Personale Innovationswiderstände', in E. Gaugler (ed.), Handwörterbuch des Personalwesens (Poeschel, Stuttgart), pp. 1046-1061.

DanWatch: 2008, 'Bad Connections - How Your Mobile Phone is Linked to Abuse, Fraud and Unfair Mining Practices in DR Congo', http://www. consumersinternational.org/shared_asp_files/GFSR.asp? NodeID $=97663 \&$ bcsi_scan_3EAB0ABF9D901350 $=0$ \&bcsi_scan_filename $=$ GFSR.asp.

Ericsson: 2007, 'Sustainable Energy Use in Mobile Communications'. EAB-07:021801 Uen Rev C. http://www.ericsson.com/technology/whitepapers/ telecom_expansion/sustainable_energy_use.shtml.

Foley, K. J.: 2005, Meta-management: A Stakeholder/ Quality Management Approach to Whole-of-Enterprise Management (SAI Global, Sydney).

Garvare, R. and P. Johansson: 2009, 'Management for Sustainability - A Stakeholder Theory', TQM \& Business Excellence Journal (accepted).

Greenpeace: 2008, 'How the Companies Line Up', http://www.greenpeace.org/international/campaigns/ toxics/electronics/how-the-companies-line-up-9. 0503-2009.

Hall, G., B. Rosenthal and J. Wade: 1993, 'How to Make Reengineering Really Work', Harvard Business Review, Nov-Dec, 119-131.

Imada, AS: 2008, 'Achieving Sustainability Through Macroergonomic Change Management and Participation', in K. J. Zink (ed.), Corporate Sustainability as a Challenge for Comprehensive Management (Physica, Heidelberg), pp. 129-138.
Isaksson, R.: 2005, 'Economic Sustainability and the Cost of Poor Quality', Corporate Social Responsibility E Environmental Management 12, 197-205.

Isaksson, R. and N. Taylor: 2006, The Process Improvement Program. Proceedings of the 9th International Conference on Quality Management and Organizational Development, 9th-11th August 2006, Liverpool.

Isaksson, R.: 2007, Product Quality and Sustainability in the Cement Industry. Proceedings of the 7th International Conference on Cement Chemistry, Montreal, Canada, 8-13 July.

Isaksson, R., J. Hallencreutz and R. Garvare: 2008, 'Process Management and System-Thinking for Sustainable Development', in K. J. Foley et al. (eds.), The Theories and Practises of Organization Excellence: New Perspectives, Chap. 8 (Consensus Books, Sydney), pp. 205-232.

Isaksson, R. and N. Taylor: 2009, Drivers for Sustainability - Making Better Use of Cement in Dar es Salaam. Proceedings of the 12th QMOD Conference, Verona, Italy.

Isaksson, R. and J. Hallencreutz: 2008, 'The Measurement System Resource as Support for Sustainable Change', The International Journal of Knowledge, Culture \& Change Management 8(1), 265-274.

Isaksson, R. and U. Steimle: 2009, 'What does GRIReporting Tell Us About Corporate Sustainability?', The TQM Journal 21(2), 168-181.

Malik, F.: 2008, Strategie des Managements komplexer Systeme: ein Beitrag zur Management-Kybernetik evolutionärer Systeme, 10th Edition (Haupt, Bern, Stuttgart, Wien).

Nokia: 2008, 'Nokia CR Report 2007', http://www. nokia.com/environment/our-responsibility/environm ental-report-2008/previous-reports, 04-03-2009.

Prahalad, C. K.: 2006, The Fortune at the Bottom of the Pyramid - Eradicating Poverty Through Profits (Wharton School Publishing, New Jersey).

Probst, G. J. B.: 1981, Kybernetische Gesetzeshypothesen als Basis für Gestaltungs- und Lenkungsregeln im Management (Haupt, Bern, Stuttgart, Wien).

Rentzhog, O.: 1996, Core Process Management (Division of Quality Technology, Linköping University, Linköping).

Skjott-Larsen, T., P. B. Schary, J. H. Mikkola and H. Kotzab: 2007, Managing the Global Supply Chain, 3rd Edition (Copenhagen Business School Press, Copenhagen).

SOMO: 2006, The High Cost of Calling - Critical Issues in the Mobile Phone Industry (SOMO, Centre for Research on Multinational Corporations, Amsterdam).

SOMO and Swedewatch: 2008, 'Silenced to Deliver - Mobile Phone Manufacturing in China and the Philippines'. 
Suchanek, A.: 2008, Business Ethics and the Golden Rule. Discussion Paper of the Wittenberg Center for Global Ethics (2008-3).

WBCSD: 2000, 'Eco-Efficiency, Creating more Value with Less Impact', www.wbcsd.org.

WBCSD: 2004. www.wbcsd.org.

WBCSD: 2008, 'Energy Efficiency in Buildings', www.wbcsd.org.

WCED: 1987, Our Common Future (Oxford University Press, Oxford).

Wilms, F. E. P.: 2003, Systemorientiertes Management (Vahlen, München).

Zink, K. J., U. Steimle and K. und Fischer: 2008, 'Human Factors, Business Excellence and Corporate Sustainability: Differing Perspectives, Joint Objectives', in K. J. Zink (ed.), Corporate Sustainability as a Challenge for Comprehensive Management (Physica, Heidelberg), pp. 3-15.
Raine Isaksson Gotland University, Cramérgatan 3, Visby, Sweden E-mail:raine.isaksson@hgo.se

Peter Johansson Luleå Technical University, Luleå, Sweden

E-mail:PeterL.Johansson@tetrapak.com

Klaus Fischer University of Kaiserslauten, Kaiserslauten, Germany E-mail:klaus.fischer@ita-kl.de 